\title{
Study of Hand Hygiene Awareness among Doctors and Nurses in King Abdulaziz Specialist Hospital
}

\author{
Wijdan Abdulmohsen Alzahrani ${ }^{1 *}$, Malak Khalid Alkuwaykibi ${ }^{1}$, Athir Athallah Alruwili ${ }^{1}$, Abeer Zaid \\ Almaziad ${ }^{1}$, Shaimaa Mohamed Abd Elfattah Hasn ${ }^{1}$ \\ ${ }^{1}$ College of Medicine, Aljouf University, Sakaka, Saudi Arabia \\ *Corresponding author: Wijdan Abdulmohsen Alzahrani, E-mail: waz74649@gmail.com, Mobile No: +966 551052142
}

\begin{abstract}
Background: hand hygiene is now regarded as one of the most important element of infection control activities. It is an effective strategy to prevent health care-associated infections (HCAIs). It is a required practice for all health care providers. It is done by using manually antibiotics jelly or washing hands by soap and tap water. Hand hygiene before and after examination of the patient is the first line of protection against infection as hand is considered the primary carrier of infections. Aim of the Work: was to assess the knowledge, attitudes and practice of doctors and nurses in King Abdulaziz Specialist Hospital. Patients and Methods: this descriptive cross-sectional study was conducted on the 110 of doctors and nurses in King Abdulaziz Specialist Hospital, who were interviewed between 3rd March 2017 and 9thApril 2017. Data were collected and analyzed using SPSS version 16. Results: out of 110 respondents, 57.3\% were female and the nurses constituted the highest cadre $(61.8 \%)$. Hand hygiene knowledge was highest in the Emergency Room (29.1\%) and lowest among diabetes center staff (3.6\%). Conclusion: hand hygiene is crucial for doctors and nurses and hence the need to improve their attitude, practice and knowledge. The presence of significant differences between doctors and nurses in our study indicated the need for qualified doctors who have enough information and knowledge about the importance of hand hygiene to assure control of infections as well as all hygienic affairs during working with patients enrolled in hospitals.
\end{abstract}

Keywords: Hand hygiene, Infection control, Health care associated infection, Health care-associated infections.

\section{INTRODUCTION}

Hand hygiene is a general term that applied to routine hand washing with soap and water or by hand rubs with gel to disinfect it. It is the single most effective and cheap means for preventing hospital acquired infection ${ }^{(1-3)}$. Hand hygiene reduces potential pathogens on the hands. It is considered a primary measure for reducing the risk of transmitting organisms to patients including Antibiotic-Resistant Organisms (ARO).Although the action of hand hygiene is simple, the lack of compliance among health-care workers continues to be a problem throughout the world ${ }^{(1)}$. There are many indications for hand hygiene which include the following: Before and after treating each patient (e.g., before glove placement and after glove removal), after barehanded touching of inanimate objects likely to be contaminated by blood, saliva, or respiratory secretions, before leaving the dental operatory, when hands are visibly soiled, before re-gloving, after removing gloves that are torn, cut, or punctured, for oral surgical procedures, perform surgical hand antisepsis before donning sterile surgical gloves ${ }^{(1)}$. Hand hygiene is now regarded as one of the most important element of infection control activities. It is an effective strategy to prevent health care-associated infections (HCAIs). It is a required practice for all health care providers, as health care providers move from client/patient/resident-to-client/patient/resident carrying out a number of tasks and procedures. There are many indications for hand hygiene during the delivery of health care and in the activities of daily living outside of the health care setting. However, health workers wash hands too seldom, not always at the most appropriate times and technique is suboptimal $^{(4)}$. Hand hygiene is the responsibility of all individuals working in health care. It is the most effective means of reducing infections. It is practice for protection of patients from intervention of many microorganisms. It is done by using manually antibiotics gelly or washing hands by soap and tap water as hand is primary carriers of infections. So, the first line defend is hand hygiene before and after examination of patients ${ }^{(5)}$. There are many causes and means for the spread of infection among health care organization. These elements include the following : immune compromised patients , more antibioticresistant strains of several types of bacteria due to the misuse of antibiotics, improper satisfied hand hygiene, inefficient as well as sufficient cleanness and sterilization of equipment's due to lack of nursing staffs which lead to less attention to infection prevention practice ${ }^{(6,}{ }^{7)}$. According to the abovementioned information it is recognized that hand hygiene is considered the most effective intervention for avoiding hospital acquired infections, 
in addition to shorter hospital stay, reduction in patients morbidity, mortality and as well as decreased health care costs. Health care associated infections are drawing increasing attention from patients, insurer's governments and regulatory bodies due to increased morbidity, mortality, and cost of treatment. There is now undisputed evidence that strict adherence to hand hygiene reduce the risk of cross transmission of infections ${ }^{(8)}$. Hand hygiene is now regarded as one of the most important element of infection control activities. As a result of increased health care associated infection, severity of diseases increased, complexity of treatments procedures necessary to be undertaken as well as and multi-drug resistance. So, health care practitioners are reversing back to the basics of infection prevention by simple measures like hand hygiene. Because it reduces the risk of cross-transmission of infection ${ }^{(9)}$. There are two types of microbes colonizing hand: the resident flora, which consist of microorganism residing under the superficial cells of the stratum corneum and the transient flora, which colonizes the superficial layers of the skin, and is more amenable to removal by routine hand hygiene. Also, they are the organisms most frequently associated with HCAIs ${ }^{(1)}$. The hand of Health Care Workers (HCWs) is commonly colonized with pathogens like methicillin-resistant Staphylococcus aurous (MRSA), vancomycin resistant Enterococcus (VRE), MDR-Gram Negative bacteria (GNBs), Candidia spp. And Clostridium difficle, which can survive for as long as $150 \mathrm{~h}^{(10)}$. Approximately skin epithelial cells containing viable microorganisms are shed daily from the normal skin, which can contaminate the gowns, bed linen, beside furniture, and other objects in patient's immediate environment ${ }^{(1)}$. Hand carriage of resistant pathogen has repeatedly been shown to be associated with nosocomial infection. The highest rate of hand contamination is reported from critical care areas, which also report most cases of cross transmission. The hand may become contaminated by merely touching the patent's intake skin or inanimate objects in patient's room or during the "clean" procedures like recording blood pressure. Proper hand hygiene is the single most important, simplest and least expensive means of reducing the prevalence of HAIs and the spread of antimicrobial resistance ${ }^{(11)}$. Several studies have demonstrated that hand washing virtually eradicates the carriage of MRSA which always occurs on the hands of HCPs working in ICUs. An increase in hand washing compliance has been found to be accompanied by a fall in MRSA rates ${ }^{(12)}$. The importance of hand hygiene was recognized as early as 1840 s, by Dr. Oliver Wendell Holmes to prevent childbed fever and in the late 1840's, by Dr. Ignaz Semmelweis to reduce maternal mortality in a Vienna hospital, however, adherence to hand hygiene practices still remains low (40\% or below) in most of the health care institutions ${ }^{(13)}$. Improper hand hygiene by healthcare workers (HCWs) is responsible for about $40 \%$ of nosocomial infections The spread of infections in developing countries remains a serious problem, especially in high risk settings such as health care facilities due to lack of awareness in health care workers ${ }^{(14)}$. The adherence to proper hand hygiene by the health workers has been reported to be poor in many studies ${ }^{(15)}$. It has also been observed that the compliance to hand hygiene increases with regular training activities ${ }^{(16)}$. Some researchers have reported moderate knowledge about hand hygiene among doctors and nurses in health care ${ }^{(17)}$. On the other hand, in a study carried out in South West Nigeria found that the majority of respondents $(83.0 \%)$ had good knowledge of hand hygiene, which could have been due to greater number of training activities $^{(18)}$. In 1975 and 1985, the Centers for Disease control and Prevention (CDC) published guidelines on hand washing practices in hospitals, primarily advocating hand washing with nonantimicrobial soaps; washing with antimicrobial soap was advised before and after performing invasive procedures or during care for high risk patients. Alcohol-based solutions were recommended only in situations where sinks were not available ${ }^{(19)}$. In 1995 , the Hospital Infection Control Practices Advisory Committee (HICPAC) advocated the use of antimicrobial soap or a waterless antiseptic agent for cleaning hands upon leaving the rooms of patients infected with multidrug-resistant pathogens ${ }^{(20)}$. In 2002, the CDC published revised guidelines for hand hygiene. A major change in these guidelines was the recommendation to use alcohol based hand rubs for decontamination of hands between each patient contact (of non-soiling type) and the use of liquid soap and water for cleaning visibly contaminated or soiled hands ${ }^{(1)}$. Alamer $\boldsymbol{e t} \boldsymbol{a l}$. were found that $15 \%$ of the physicians possessed good knowledge and 68\% fair knowledge about hand hygiene. The defect in their knowledge was about the minimal time needed for alcohol-based hand rubbing to kill most of the hand germs. All nonhuman resources for hand hygiene were available, except for the lotions or 
creams that are used for lubrication to prevent dryness after hand hygiene ${ }^{(21)}$. Omuemu et al. were found that a total of 326 out of 454 eligible participants completed and returned questionnaire giving a response rate of $71.8 \%$. Majority of them $(55.2 \%)$ were in the age group 30-39 years with mean age of $33.7 \pm 8.8$ years. There were more males $(69.9 \%)$ than females $(30.1 \%)$ and the resident doctors constituted the highest cadre of doctors (56.7\%). Overall, $48.2 \%$ of the respondents reported good practice of hand hygiene, while $39.8 \%$ and $12.0 \%$ reported fair and poor practices, respectively. A greater proportion of the female respondents $(53.1 \%)$ than the male respondents $(46.1 \%)$ had good practice of hand hygiene ${ }^{(22)}$.

\section{AIM OF THE WORK}

The aim of the present study was to assess the knowledge, attitudes and practice of doctors and nurses in King Abdulaziz Specialist Hospital regarding hand hygiene.

\section{PATIENTS AND METHODS}

Study design: The design of this study is a descriptive cross-sectional KAP study conducted between 2016 and 2017. A self-administered questionnaire was distributed to doctors and nurses in King Abdulaziz Specialist Hospital during an interview with them. Study duration: From 2016 to $11^{\text {th }}$ April 2017. Study setting: King Abdulaziz Specialist Hospital. Sample size: Sample size was calculated using the EPI info 2000 statistical package and it was 290 but only 110 of subjects accepted to fill in the questionnaire. Inclusion criterion: Doctors and nurses in King Abdulaziz Specialist Hospital. Exclusion criterion: Health workers and personnel of K.A.S.H. Sakaka, other than doctors and nurses. Ethical review and informed consent: This study was conducted with approval of ethics review committee of Al- Jouf College of medicine. A verbal consent was taken from all participants before the enrollment in the study. To enhance the confidentiality, all questionnaires were completed anonymously with only required information. Data collection procedure: We developed the questionnaire using the questionnaire used in Development of a theorybased instrument to identify barriers and levers to best hand hygiene practice among healthcare practitioners and modified it to fit our need as hand hygiene varies from hospital to hospital, even between different wards and departments. Also, it varies according to the role of different practitioners. It consists of two parts. The first part of the questionnaire includes demographic characteristics such as job title, gender, years of work and area of work in the hospital. The second part of the questionnaire includes circle the number that demonstrates to what extent strong agree or strong disagree with the statements given. The questionnaire was in the Arabic and English version of hand hygiene that was validated in previous study carried out in the University of Leeds. It is anticipated that this will take about 3 minutes ${ }^{(23)}$. Data analysis procedure / Statistical procedure: The collected data through the performance of the questionnaire was entered in SPSS. To maintain confidentiality the data were entered according to number and questionnaire was saved in a safe cabinet. Data analysis was performed using SPSS version 16. Descriptive statistics were performed.

\section{RESULTS}

Total of 110 out of 290 giving response rate of $38 \%$. The demographic characteristics showed that nurses constituted the highest cadre $(61.8 \%)$ and the females $(57.3 \%)$ were more than male $(42.7 \%)$ as shown in [table1]. Diagram 1 shows who have sufficient knowledge and skills about hand hygiene among doctors and nurses. Diagram 2 shows who have a good practice $(90.9 \%)$ as well as who have a poor practice $(9.1 \%)$ about hand hygiene. Staff working in Emergency Room (ER) have the most knowledge about hand hygiene $(29.1 \%)$ and the lowest knowledge is in the diabetes center (3.6\%) as shown in [table 2].

Table (1): Socio-demographic characteristics of respondents

\begin{tabular}{|l|c|c|}
\hline & Count & \% \\
\hline Job title & & \\
Doctors & 42 & 38.2 \\
Nurses & 68 & 61.8 \\
\hline Gender & 47 & \\
Male & 63 & 42.7 \\
Female & & \\
\hline Years of work & 42.3 \\
$1-10$ & 27 & 38.2 \\
$11-20$ & 34 & 24.5 \\
$21-30$ & 7 & 30.9 \\
31 and over & & 6.4 \\
\hline
\end{tabular}




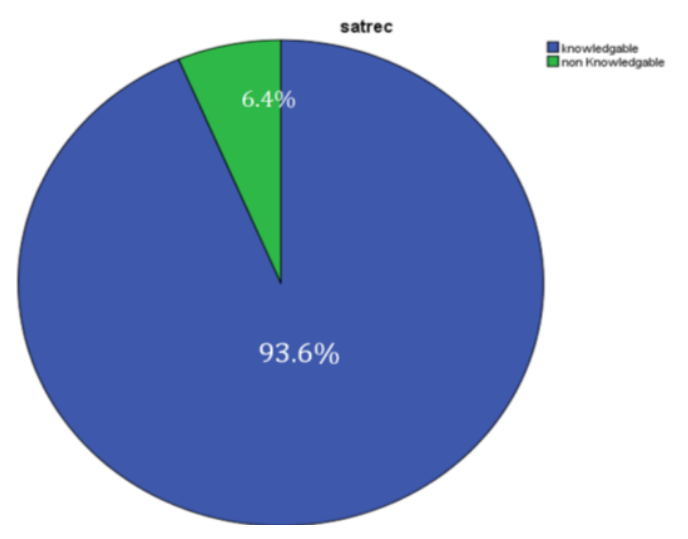

Diagram (1): Knowledge about hand hygiene amongst staff of K.A.S.H.

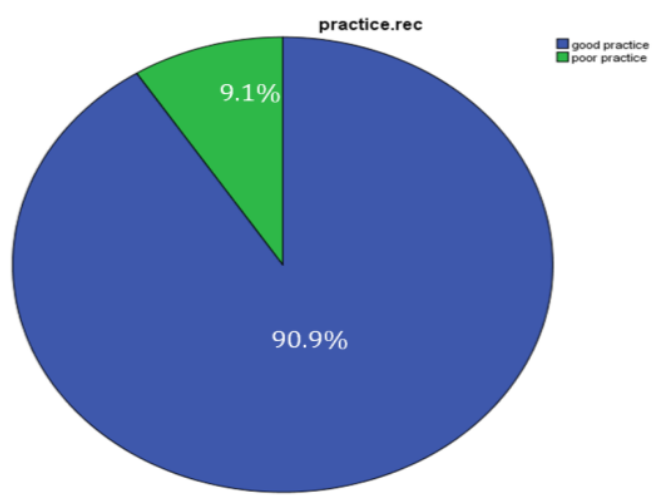

Diagram (2): Practice about hand hygiene amongst staff of K.A.S.H.

Table (2): Percentage of staff having knowledge about hand hygiene according to departments

\begin{tabular}{|l|c|c|}
\hline \multicolumn{1}{|c|}{ Area of work } & Count & \% \\
\hline Outpatient Department (OPD) & 24 & 21.8 \\
\hline Dental center & 11 & 10.0 \\
\hline Emergency Room(ER) & 32 & 29.1 \\
\hline Operating Room (OR) & 6 & 5.5 \\
\hline Intensive Care Unit (ICU) & 10 & 9.1 \\
\hline Diabetic center & 4 & 3.6 \\
\hline Surgical department & 14 & 12.7 \\
\hline Infection control & 9 & 8.2 \\
\hline
\end{tabular}

Table (3): Percentage distribution of response of each question in the questionnaire

\begin{tabular}{|c|c|c|c|c|c|}
\hline & \begin{tabular}{|c|} 
Strong \\
agree
\end{tabular} & Agree & Neutral & Disagree & \begin{tabular}{|c|}
$\begin{array}{c}\text { Strong } \\
\text { disagree }\end{array}$ \\
\end{tabular} \\
\hline $\begin{array}{l}\text { Q5: Hand hygiene is } \\
\text { embedded into my } \\
\text { professional practice. }\end{array}$ & $80.9 \%$ & $11.8 \%$ & $1.8 \%$ & $0 \%$ & $5.5 \%$ \\
\hline $\begin{array}{l}\text { Q6: Sometimes I miss out } \\
\text { hand hygiene simply } \\
\text { because I forget it. }\end{array}$ & $4.5 \%$ & $20.0 \%$ & $30.9 \%$ & $12.7 \%$ & $31.8 \%$ \\
\hline $\begin{array}{l}\text { Q7: Hand hygiene audits } \\
\text { are regularly carried out in } \\
\text { my work place. }\end{array}$ & $51.8 \%$ & $20.9 \%$ & $17.3 \%$ & $5.5 \%$ & $4.5 \%$ \\
\hline $\begin{array}{l}\text { Q8: . Supervision from } \\
\text { senior staff means that } \\
\text { carrying out hand hygiene } \\
\text { is easier for me. }\end{array}$ & $43.6 \%$ & $14.5 \%$ & $24.5 \%$ & $7.3 \%$ & $10.0 \%$ \\
\hline $\begin{array}{l}\text { Q9: I have sufficient } \\
\text { knowledge about hand } \\
\text { hygiene. }\end{array}$ & $70.0 \%$ & $14.5 \%$ & $8.2 \%$ & $2.7 \%$ & $4.5 \%$ \\
\hline $\begin{array}{l}\text { Q10:Peer pressure } \\
\text { influences my hand } \\
\text { hygiene. }\end{array}$ & $19.1 \%$ & $24.5 \%$ & $21.8 \%$ & $12.7 \%$ & $21.8 \%$ \\
\hline $\begin{array}{l}\text { Q11: . There are adverts or } \\
\text { newsletters about hand } \\
\text { hygiene in my workplace. }\end{array}$ & $59.1 \%$ & $20.0 \%$ & $12.7 \%$ & $3.6 \%$ & $4.5 \%$ \\
\hline $\begin{array}{l}\text { Q12: I have sufficient skills } \\
\text { for hand hygiene. }\end{array}$ & $60.9 \%$ & $19.1 \%$ & $11.8 \%$ & $4.5 \%$ & $3.6 \%$ \\
\hline $\begin{array}{l}\text { Q13: . It is difficult to } \\
\text { prompt senior staff when } \\
\text { they miss out hand hygiene. }\end{array}$ & $16.4 \%$ & $21.8 \%$ & $27.3 \%$ & $10.9 \%$ & $23.6 \%$ \\
\hline $\begin{array}{l}\text { Q14: . Emergencies and } \\
\text { other priorities make hand } \\
\text { hygiene more difficult at } \\
\text { times. }\end{array}$ & $20.9 \%$ & $28.2 \%$ & $30.0 \%$ & $10.9 \%$ & $10.0 \%$ \\
\hline $\begin{array}{l}\text { Q15: . Facilities are } \\
\text { inadequate for hand } \\
\text { hygiene in my area of } \\
\text { work. }\end{array}$ & $19.1 \%$ & $8.2 \%$ & $10.9 \%$ & $15.5 \%$ & $46.4 \%$ \\
\hline $\begin{array}{l}\text { Q16: . Infection prevention } \\
\text { teams have a positive } \\
\text { influence on my hand } \\
\text { hygiene. }\end{array}$ & $51.8 \%$ & $20.9 \%$ & $16.4 \%$ & $3.6 \%$ & $7.3 \%$ \\
\hline $\begin{array}{l}\text { Q17: . It is difficult for me } \\
\text { to attend hand hygiene } \\
\text { courses due to time } \\
\text { pressure. }\end{array}$ & $20.9 \%$ & $22.7 \%$ & $21.8 \%$ & $14.5 \%$ & $20.0 \%$ \\
\hline $\begin{array}{l}\text { Q18: I work in several } \\
\text { areas of the hospital. }\end{array}$ & $34.5 \%$ & $15.5 \%$ & $14.5 \%$ & $14.5 \%$ & $20.9 \%$ \\
\hline $\begin{array}{l}\text { Q19:hand hygiene } \\
\text { guidelines are easily } \\
\text { accessible. }\end{array}$ & $70.0 \%$ & $18.2 \%$ & $6.4 \%$ & $1.8 \%$ & $3.6 \%$ \\
\hline $\begin{array}{l}\text { Q20:some strategies to } \\
\text { improve the practice Some } \\
\text { strategies designed to } \\
\text { improve hand hygiene } \\
\text { influence my practice. }\end{array}$ & $53.6 \%$ & $23.6 \%$ & $13.6 \%$ & $4.5 \%$ & $4.5 \%$ \\
\hline $\begin{array}{l}\text { Q21: . Hospital targets } \\
\text { relating to infection or hand } \\
\text { hygiene has led to } \\
\text { mprovements in my hand } \\
\text { hygiene. }\end{array}$ & $58.2 \%$ & $20.9 \%$ & $14.5 \%$ & $3.6 \%$ & $2.7 \%$ \\
\hline
\end{tabular}

\section{DISCUSSION}

This study showed that most participants had a good level of knowledge about hand hygiene 
$93.6 \%$, while the non-knowledgeable was $6.4 \%$. Contrary to this finding, in a study by Alamer $\boldsymbol{e t}$ al. that were found $15 \%$ of the physicians possessed good knowledge and $68 \%$ fair knowledge about hand hygiene ${ }^{(23)}$. The findings of our study showed that most participants had a good level of practice of hand hygiene $90.8 \%$, while $9.1 \%$ reported fair and poor practices. The results of our study are not consistent with the results of a study conducted by $\mathrm{Omuemu}$ et $\boldsymbol{a l}$. who found that $48.2 \%$ possessed good practice and $51.8 \%$ fair and poor practices ${ }^{(24)}$. In our study the majority of respondents according to years of work were 1-10 years . There were more female $57.3 \%$ than male $42.7 \%$ and the nurses constituted the highest cadre $61.8 \%$. The percentage of staff having knowledge about hand hygiene in King Abdulaziz Specialist Hospital, Sakaka is more due to specific adverts and newsletters about hand hygiene. In addition to infection control teams have a positive influence on the hand hygiene in this hospital. The knowledge about hand hygiene was found to be significantly better among the Emergency Room (ER) $29.1 \%$ when compared to the others departments. Their better score may be due to good preclinical skills training program and hand hygiene audits are regularly carried out in their work place. As compared to the departments, the Intensive Care Unit (ICU) had moderate knowledge about hand hygiene $9.1 \%$. Although hand hygiene is a very simple procedure and has long been deemed one of the most important infection control measures, the compliance rates by diabetic center are generally reported to be low $3.6 \%$. This is may be due to miss out hand hygiene because they forget it and also time pressure plays a role ${ }^{(21,22)}$.

\section{CONCLUSION}

From the above, Hand hygiene is the basic core of preventing HAI, for every person handling patient or preparing a service to the patient. All doctors and nurses should believe and advocate the importance of updating and applying proper hand hygiene, to reduce time and cost of staying at hospital and reduce morbidity and mortality. Our study shows that most of doctors and nurses have high knowledge about hand hygiene. Inspite of that , there is a need to improve and maintains the clinical daily routines for nurses and doctors. The presence of significant differences between doctors and nurses in our study indicates the need of doctors for more knowledge about the importance of hand hygiene to avoid infection.

\section{CONFLICTS OF INTEREST}

There are no conflicts of interest.

\section{REFERENCES}

1. Boyce JM, Pittet D(2002): Guideline for hand hygiene in health-care settings: recommendations of the Healthcare Infection Control Practices Advisory Committee and the HICPAC/SHEA/APIC/IDSA Hand Hygiene Task Force. Infection Control \& Hospital Epidemiology,23(S12):S3-S40.

2. Larson EL, Committee AG(1995): APIC guidelines for handwashing and hand antisepsis in health care settings. American journal of infection control, 23(4):251-69.

3. Favero MS (1985): Guideline for Handwashing and Hospital Environmental Control, 1985

4. Albert RK, Condie F (1981): Hand-washing patterns in medical intensive-care units. New England Journal of Medicine, 304(24):1465-6.

5. Broughall J, Marshman C, Jackson B, Bird P (1984): An automatic monitoring system for measuring handwashing frequency in hospital wards. Journal of Hospital Infection, 5(4):447-53.

6. Gould D (1994): Nurses' hand decontamination practice: results of a local study. Journal of Hospital Infection, 28(1):15-30.

7. Taylor L (1978): An evaluation of handwashing techniques-2. Nursing times, 74(3): 108 .

8. Mathur P (2011): Hand hygiene: back to the basics of infection control. The Indian journal of medical research, 134(5):611.

9. Kampf G, Kramer A (2004): Epidemiologic background of hand hygiene and evaluation of the most important agents for scrubs and rubs. Clinical microbiology reviews, 17(4):863-93. 
10. Pratt RJ, Pellowe C, Loveday H, Robinson N, Smith G, Barrett S et al. (2011): The epic project: developing national evidence-based guidelines for preventing healthcare associated infections. Phase I: Guidelines for preventing hospital-acquired infections. Department of Health (England). The Journal of hospital infection, 47:S3-82.

11. Safety WP (2009): Organization WH. WHO guidelines on hand hygiene in health care. whqlibdoc.who.int/ publications/2009/9789241597906_eng.p df

12. Pittet D, Hugonnet S, Harbarth $S$, Mourouga P, Sauvan V, Touveneau $S$ et al. (2000): Effectiveness of a hospitalwide programme to improve compliance with hand hygiene. The Lancet, 356(9238):1307-12.

13. Katz JD (2004): Hand washing and hand disinfection: more than your mother taught you. Anesthesiology Clinics of North America, 22(3):457-71.

14. Inweregbu $\mathrm{K}$, Dave $\mathbf{J}$, Pittard $A$ (2005): Nosocomial infections. Continuing Education in Anaesthesia, Critical Care \& Pain, 5(1):14-7.

15. Bataduwaarachchi VR, Balasubramanium M, Balasooriya D, Senerath U (2011): Compliance with the aseptic precautions during intravenous access among the nursing staff at the National Hospital of Sri Lanka (NHSL). International Journal of Infection Control, 7(3).

16. Randle J, Clarke M, Storr J(2006): Hand hygiene compliance in healthcare workers. Journal of Hospital Infection, 64(3):205-9.
17. Nair SS, Hanumantappa R, Hiremath SG, Siraj MA, Raghunath P (2014): Knowledge, attitude, and practice of hand hygiene among medical and nursing students at a tertiary health care centre in Raichur, India. ISRN preventive medicine, 2014.

18. Ekwere TA, Okafor IP (2013): Hand hygiene knowledge and practices among healthcare providers in a tertiary hospital, south west, Nigeria. International Journal of Infection Control, 9(4).

19. Steere AC, Mallison GF (1975): Handwashing practices for the prevention of nosocomial infections. Annals of Internal Medicine, 83(5):683-90.

20. Hospital Infection Control Practices Advisory Committee (1995): Recommendations for preventing the spread of vancomycin resistance. Infect Control Hosp Epidemiol., 16:105-113.

21. Alamer N, Zabeeri N, Aburuz M, Qarneh H (2015): Physicians knowledge about hand hygiene at King Fahad Hospital of University, Dammam, KSA. Int J Med Sci Pub Health, 4:1242-6.

22. Omuemu VO, Ogboghodo EO, Opene RA, Oriarewo P, Onibere $O$ (2013): Hand hygiene practices among doctors in a tertiary health facility in southern Nigeria. Journal of Medicine in the Tropics, 15(2):96.

23. Dyson J, Lawton R, Jackson C, Cheater F (2013): Development of a theory-based instrument to identify barriers and levers to best hand hygiene practice among healthcare practitioners. Implementation Science, 8(1): 1 . 